\title{
Revising the Proton Affinity Scale of the Naturally Occurring $\alpha$-Amino Acids
}

\author{
Christian Bleiholder, Sándor Suhai, and Béla Paizs \\ Department of Molecular Biophysics, German Cancer Research Center, Heidelberg, Germany
}

The proton affinities (PA) of the 20 naturally occurring $\alpha$-amino acids (AA) have been determined computationally by means of density functional theory (DFT) and high-level G2(MP2) calculations. These theoretical PAs, together with data that have appeared since 1997 in the literature, are used to validate the most reasonable currently available PA scale for AAs (Harrison, A. G. Mass Spectrom. Rev. 1997, 16, 201-217.). Significant scatter is observed for the PAs of Ser, Asp, Phe, Asn, Met, Pro, Gln, Glu, Trp, His, Lys, and Arg, many of which have a basic side-chain functionality. Critical review of the available data leads to new consensus PAs for Asn, Gln, Met, and Arg of 222.4, 230.5, 223.7, and $250.2 \mathrm{kcal} / \mathrm{mol}$, respectively. (J Am Soc Mass Spectrom 2006, 17, 1275-1281) @ 2006 American Society for Mass Spectrometry

$\mathrm{P}$ rotonation energetics of the naturally occurring amino acids (AA) is of current interest because of the importance of proton transfer (PT) reactions in biological systems [1]. Recently, the PAs of amino acids, small peptides, and their derivatives have been successfully used [2-7] to explain some fragment ion abundance relationships in the low-energy tandem mass spectra of protonated peptides. Considering appropriate PAs, one can often predict whether the N- or the C-terminal fragment remains charged upon dissociation of the respective parent ions [2]. These predictions require, however, good quality PA data for the fragments involved.

The literature on the protonation chemistry of AAs and small peptides was reviewed by Harrison [8] who introduced the recently available, most consistent gasphase basicity (GB) and proton affinity (PA) scales for AAs. Harrison used the following strategy [8] to compile his list. First, he critically evaluated the available literature data on gas-phase basicities of AAs since most of the existing experimental techniques address primarily GBs and not PAs. Then eq 1,

$$
\mathrm{PA}=\mathrm{GB}-\mathrm{T} \Delta \mathrm{S}=\mathrm{GB}-T\left(\Delta S_{\mathrm{vib}}+\Delta S_{\text {rot }}+\Delta S_{\text {trans }}\right)
$$

was used to convert GBs to PAs applying appropriate $\Delta S$ values. Here, $T$ is the temperature and $\Delta S$ is the protonation entropy. The protonation entropy can be represented as a sum of three terms, involving entropy changes caused by loss of translational $\left(\Delta \mathrm{S}_{\text {trans }}\right)$, rotational $\left(\Delta \mathrm{S}_{\mathrm{rot}}\right)$, and vibrational $\left(\Delta \mathrm{S}_{\mathrm{vib}}\right)$ degrees of freedom, whereby the $\Delta S_{\text {vib }}$ term is usually neglected (for more details, see reference [8]).

Published online July 10, 2006

Address reprint requests to Dr. B. Paizs, Department of Molecular Biophysics, German Cancer Research Center, Im Neuenheimer Feld 580, D-69120 Heidelberg, Germany. E-mail: B.Paizs@dkfz.de
Direct assessment of $\Delta \mathrm{S}$ is possible only if the GBs are determined from variable-temperature equilibrium measurements [8]. Such studies have been performed only for Gly, Ala, and Pro; the results suggest that the $\Delta S$ term is dominated by the loss of translational entropy of the free proton for these AAs $\left(\Delta S \approx \Delta S_{\text {transi }}\right.$; $\Delta S_{\text {rot }} \approx 0$ ) [9]. In other words, for those amino acids for which no extra strong $\mathrm{H}$-bond is introduced in the protonated species, $\Delta S$ resulting from changes of the rotational degrees of freedom is negligible $\left(\Delta S_{\text {rot }} \approx 0\right)$. The term $\Delta S_{\text {trans }}$ can be readily approximated by the Sackur-Tetrode equation (for details see reference [8]), which gives $\mathrm{T} \Delta \mathrm{S}_{\text {trans }}$ of $-7.8 \mathrm{kcal} \mathrm{mol}^{-1}$ for $\mathrm{T}=298 \mathrm{~K}$.

The $\Delta \mathrm{S}_{\text {rot }} \approx 0$ approximation is definitely not valid for AAs containing strongly basic side chains like Lys or Arg, for which a strong intramolecular H-bond is introduced in the protonated species (for example, $-\mathrm{H}_{2} \mathrm{~N}_{\varepsilon}{ }^{+}-\mathrm{H}$. . . $\mathrm{NH}_{2}-$ for protonated Lys). These strong hydrogen bonds freeze rotational degrees of freedom in the protonated species that can be considered free in the neutral molecules, thus leading to a negative rotational entropy $\left(\Delta S_{\text {rot }}<0\right)$. The magnitude of $\Delta S_{\text {rot }}$ for AAs is mostly approximated by considering similar molecules for which data from variable temperature equilibrium experiments are available. For example, Harrison approximated $\Delta \mathrm{S}_{\text {rot }}$ (Lys) using $\Delta \mathrm{S}_{\text {rot }}(1,5$-diaminopentane) at $-20 \mathrm{cal} \mathrm{mol}^{-1} \mathrm{~K}^{-1}$ [10]. Unfortunately, no experimental or theoretical information on $\Delta \mathrm{S}_{\text {rot }}$ for Arg, Gln, Asn, etc. is available. Harrison assumed that the rotational component of $\Delta \mathrm{S}$ for all AAs except Lys is negligible, although stating that this approach can introduce errors in the PAs of Asn, Met, Gln, Glu, Trp, His, and Arg.

The last decade has seen enormous advances in computational chemistry. Introduction of new methods such as density functional theory (DFT), extrapolation schemes like G2(MP2), efficient algorithms and software, and widely available hardware allows one to 
perform rather accurate calculations for molecules such as AAs. At first sight, determination of PAs using pure theoretical methods does not seem to be difficult. A good approximation can be obtained if the energetics of the most stable conformers of the neutral and protonated forms of the molecule under investigation are obtained. Practical difficulties to be faced include detailed search of extremely complex conformation spaces and performing high-level calculations for molecules as large as Arg, His, etc. If these mostly technical problems are successfully overcome, one can obtain rather reasonable PAs, the quality of which can easily be better than of those derived from experimental GBs using ambiguous approximations for $\Delta \mathrm{S}_{\text {rot }}$.

In the present paper, we report on detailed scans of the conformation spaces of the protonated and neutral forms of the naturally occurring $\alpha$-amino acids using DFT and G2(MP2) methods. (It is worth noting here that G2(MP2) calculations are available only for Gly [11] in the literature.) In these calculations we have used our search engine developed specifically to deal with the very many conformers of protonated peptides [2, 5, 7]. Analyzing our and other literature data, we point out some inconsistencies within the current PA scale by Harrison and indicate their possible origin. To improve the PA scale, new values are suggested for Asn, Gln, Met, and Arg.

\section{Computational Details}

To find the global minimum of the respective amino acids and their protonated forms, we applied the following protocol. The conformation space of the protonated and neutral forms of the examined AAs was explored by simulated annealing techniques using the InsightII program (Biosym Technologies, San Diego, $\mathrm{CA}$ ) in conjunction with the AMBER force field. For the amino acids bearing basic side chains (Arg, His, Lys) two protonation sites were checked (backbone amino and side-chain functional group). During the dynamics cycles, we regularly saved structures for further refinement by full geometry optimization using the same force field. In the next step of the scan, these structures were analyzed by our own conformer family search program. This program is able to group optimized structures into families in which the most important characteristic torsion angles of the molecule are similar. The most stable species in the families were then fully optimized at the HF/3-21G, B3LYP/6-31G(d), and finally at the B3LYP/6-31+G $(d, p)$ levels. The B3LYP/6$31+G(d, p)$ total energies were corrected for zero-point vibrational energies (ZPE) determined at the B3LYP / 6$31 \mathrm{G}(\mathrm{d})$ level. The most stable structures of the neutral and protonated forms obtained at the B3LYP/6$31+G(d, p)$ level were further investigated using G2(MP2) calculations. PAs were obtained as the difference between the ZPE-corrected DFT total electronic energies or G2(MP2) energies of the protonated and neutral forms of AAs, respectively. For all quantum chemical calculations, the Gaussian [12] program was used.

\section{Results and Discussion}

After publication of Harrison's scale, Tabet et al. [13] and Bouchoux and coworkers [14, 15] determined the PAs of most of the amino acids by applying variations of Cooks' kinetic method [16, 17]. Additionally, Maksic and Kovacevic [18] calculated AA PAs at the MP2/631+G(d,p)//RHF/6-31G(d) level. In 1998 Hunter and Lias (H\&L in the following) [19] published an update of the evaluated gas-phase basicities and proton affinities [20]. For completeness, these data are collected in Table 1. (PAs published before reference 8 are not presented because they were discussed in detail in reference [8]). Table 1 also contains our PA values obtained at the B3LYP / 6-31+G(d,p) and G2(MP2) levels [21, 22]. (Total energies, geometries, and graphical representations of the most stable neutral and protonated structures are available in the Supplementary Material section which can be found in the electronic version of this article.)

\section{Assessment of the Reliability of Sources for PA Data}

In evaluating the PA data of Table 1, we use Harrison's value as a starting point and follow a strategy that is similar to that implemented in reference [8], e.g., all reasonable PA values will be taken into account while those values that appear to be out of line with other data will be considered suspicious. Recently published PA values that differ no more than $2.5 \mathrm{kcal} / \mathrm{mol}$ from that of Harrison's value will be regarded as further support of the original value. PAs differing more than $2.5 \mathrm{kcal} / \mathrm{mol}$ from Harrison's value will be considered suspicious and evaluated in detail. The slightly arbitrarily chosen $\pm 2.5 \mathrm{kcal} / \mathrm{mol}$ range reflects the uncertainties of the applied experimental and theoretical approaches to derive PA data, and is similar to that used in a previous work by H\&L [19]. It is worth noting here that the procedure applied by H\&L [19] to derive PA values is similar to Harrison's strategy, however, the latter work is better documented and the argumentation to choose GB and $\Delta \mathrm{S}$ for a particular AA is more underpinned. The differences between the Harrison and H\&L PAs of Ser, Glu, Trp, His, and Arg are larger than $2.5 \mathrm{kcal} / \mathrm{mol}$, while the other AAs show smaller deviations. For Ser, Glu, Trp, and His, reliable new data (see below) support Harrison's value while for Arg we suggest assigning a new PA ( $250.2 \mathrm{kcal} / \mathrm{mol}$, see below) that is close to the H\&L value.

The datasets of Table 1 will not be considered equally reliable. For example, Tabet and coworkers [13] applied the simplest variant of the kinetic method without considering entropy corrections that are necessary to deal with multifunctional compounds like AAs according to recent consensus in the community [23- 
Table 1. Proton affinity scales for the naturally occurring $\alpha$-amino acids

\begin{tabular}{|c|c|c|c|c|c|c|c|}
\hline $\mathrm{AA}$ & Harrison & Hunter/Lias ${ }^{\mathrm{c}}$ & Maksic & Tabet & Bouchoux & $\mathrm{DFT}^{\mathrm{d}}$ & $\overline{\mathrm{G} 2(\mathrm{MP} 2)^{\mathrm{d}}}$ \\
\hline Gly & 210.5 & 211.9 & 210.5 & 212.3 & $211.1^{a}, 211.8^{b}$ & 211.4 & 211.8 \\
\hline Cys & 214.0 & 215.9 & 213.2 & 214.4 & & 214.4 & 214.1 \\
\hline Ala & 214.2 & 215.5 & 214.0 & 214.0 & $213.8^{a}$ & 215.0 & 215.2 \\
\hline Ser & 215.2 & 218.6 & 216.0 & 216.4 & $216.2^{\mathrm{a}}$ & 217.3 & 217.7 \\
\hline Asp & 216.4 & 217.2 & 217.3 & 217.4 & $221.5^{\mathrm{b}}$ & 218.0 & 218.5 \\
\hline Val & 216.5 & 217.6 & 215.2 & 217.6 & & 217.7 & 218.0 \\
\hline Leu & 217.4 & 218.6 & 216.8 & 217.8 & & 218.2 & 218.2 \\
\hline Ile & 218.6 & 219.3 & 216.5 & 218.4 & & 218.7 & 218.8 \\
\hline Thr & 219.5 & 220.5 & 217.5 & 218.5 & & 218.7 & 218.5 \\
\hline Phe & 219.9 & 220.6 & 223.3 & 219.8 & & 220.6 & 219.8 \\
\hline Asn & 220.6 & 222.0 & 223.2 & 223.0 & $230.7^{b}$ & 224.2 & 222.4 \\
\hline Tyr & 220.9 & 221.3 & $\overline{221.9}$ & 220.3 & & $\overline{221.2}$ & 220.2 \\
\hline Met & 221.1 & 223.6 & 221.7 & 221.7 & & 224.0 & 223.7 \\
\hline GIn & 222.0 & 224.1 & 233.0 & 226.2 & $236.2^{b}$ & 231.9 & 230.5 \\
\hline Pro & 222.1 & 220.0 & $\overline{221.9}$ & $\overline{223.9}, 225.7^{e}$ & $\overline{221.3^{a}}$ & $\overline{224.0}$ & $\overline{223.8}$ \\
\hline Glu & 223.4 & 218.2 & 225.9 & 223.3 & $234.7^{b}$ & 225.8 & 224.7 \\
\hline Trp & 223.9 & $\overline{226.8}$ & 220.7 & 223.8 & & 223.8 & - \\
\hline $\mathrm{His}$ & 231.5 & 236.1 & 229.8 & 229.2 & $236.5^{\mathrm{a}}, 238.1^{\mathrm{b}}$ & 233.7 & 231.8 \\
\hline Lys & 235.6 & $\overline{238.0}$ & 237.8 & 228.6 & $237.7^{a}, 237.6^{b}$ & 237.3 & 237.1 \\
\hline Arg & 244.8 & 251.2 & 248.6 & & & 253.3 & 250.2 \\
\hline
\end{tabular}

All values in $\mathrm{kcal} / \mathrm{mol}$. Those PAs that differ more than $2.5 \mathrm{kcal} / \mathrm{mol}$ from the Harrison values are underlined.

aValues taken from Reference [14].

bValues taken from Reference [15].

'Values taken from Reference [19].

dThis work.

eReference [29].

26]. Bouchoux's PAs for Gly, Ala, Pro, Ser, Lys, and His [14] were derived from GBs determined by the reliable thermokinetic method. However, the entropies used to convert GBs to PAs are again taken from variable temperature equilibrium studies on similar molecules. Bouchoux and coworkers [15] have recently applied the extended kinetic method to derive PAs for Gly, Asp, Asn, His, Lys, Glu, and Gln. As pointed out by these authors, most of their values show significant deviation from the tabulated Harrison values for reasons which are not at all apparent.

From the theoretical data of Table 1, we consider our DFT and G2(MP2) PAs more reliable than Maksic's $\mathrm{MP} 2 / 6-31+\mathrm{G}(\mathrm{d}, \mathrm{p}) / / \mathrm{RHF} / 6-31 \mathrm{G}(\mathrm{d})$ values because of two reasons. First, Maksic used the RHF/6-31G(d) level of theory to optimize geometries of molecules with strong and/or weak H-bonds. It is well known that Hartree-Fock theory often poorly describes such molecular systems [27]. Furthermore, no details are reported on the neutral and protonated structures used to obtain the final protonation energetics at the MP2/6$31+G(d, p)$ level of theory and the strategy employed to scan the potential energy surfaces of these molecules. On the other hand, our computational studies employ a well-established search engine in the scans and our final G2(MP2) theoretical level is no doubt more reliable than that applied by Maksic. To summarize our discussion on various sources of PA data listed in Table 1, we consider Bouchoux's thermokinetic and our G2(MP2) data as the most reliable.

\section{Evaluation of Harrison's PA Scale for Amino Acids}

The twenty AAs can be sorted into three major groups considering scatter of the PAs presented in Table 1. The first group includes Gly, Cys, Ala, Val, Leu, Ile, Thr, and Tyr for which the scatter of the individual PAs is rather small and the recently determined values do not differ more than $2.5 \mathrm{kcal} / \mathrm{mol}$ from Harrison's value. It is worth noting here that the corresponding AAs do not have basic side-chain functionalities, thus avoiding formation of strong intramolecular H-bonds upon protonation. Harrison's PAs are further supported in this group.

The second group includes Ser, Asp, Phe, Pro, Glu, His, Lys, and Trp for which recently determined PAs differ more than $2.5 \mathrm{kcal} / \mathrm{mol}$ from Harrison's value. However, these suspicious values arose from the less reliable sources discussed above while Bouchoux's thermokinetic and/or our G2(MP2) values clearly support Harrison's original PA. H\&L's PA value for Ser (218.6 $\mathrm{kcal} / \mathrm{mol}$ ) is $3.4 \mathrm{kcal} / \mathrm{mol}$ greater than Harrison's value of $215.2 \mathrm{kcal} / \mathrm{mol}$ while other data in Table 1 clearly support the latter. H\&L's PA for Trp $(226.8 \mathrm{kcal} / \mathrm{mol})$ and Maksic's PA values for Phe and Trp (223.3 and $220.7 \mathrm{kcal} / \mathrm{mol}$, respectively) differ from the other theoretical or experimental data, which slightly scatter around Harrison's original values of 219.9 and 223.9 $\mathrm{kcal} / \mathrm{mol}$, respectively. Bouchoux's PAs derived by the extended kinetic method for Asp and Glu (221.5 and $234.7 \mathrm{kcal} / \mathrm{mol}$, respectively) and H\&L's value for Glu 

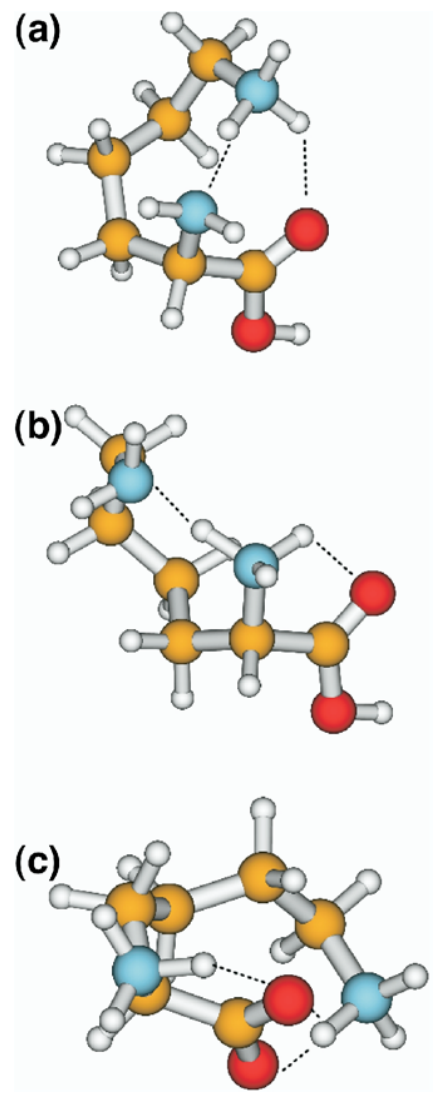

Figure 1. The energetically most stable species of $[\mathrm{Lys}+\mathrm{H}]^{+}$for the (a) side-chain, (b) N-terminal amino protonated, and (c) salt-bridge forms.

(218.2 kcal/mol) show significant deviation from Harrison's values while the other values clearly support the latter. It is worth noting here that Marynick and coworkers determined the PA of Glu using the MP2(full)/ 6-311+G(2d,p)//B3LYP/6-31+G(d,p) level and applying a detailed scan of the conformation spaces of the neutral and protonated forms [28]. Their PA at 224.4 $\mathrm{kcal} / \mathrm{mol}$ further supports Harrison's original value of $223.4 \mathrm{kcal} / \mathrm{mol}$. For Pro, two recently determined PA values have been determined to 225.7 [29] and 224.9 [30] $\mathrm{kcal} / \mathrm{mol}$, respectively, which differ by more than 2.5 $\mathrm{kcal} / \mathrm{mol}$ from Harrison's proposed value. However, all other data in Table 1 support the original value, and we suggest keeping Harrison's proposed value. Tabet and coworkers determined the PA of Lys using the simplest version of the kinetic method and obtained $228.6 \mathrm{kcal} /$ mol. This differs significantly from Harrison's original value of $235.6 \mathrm{kcal} / \mathrm{mol}$, which is supported by both Bouchoux's thermokinetic and our G2(MP2) values (237.6 and $237.1 \mathrm{kcal} / \mathrm{mol}$, respectively). Poutsma and coworkers [31] determined the PA of Lys using DFT calculations to be $239.9 \mathrm{kcal} / \mathrm{mol}$ that significantly differs from Harrison's value. We have carefully studied their best structures for the neutral and protonated forms and found that our corresponding structures are energetically more favored. This is especially true for the neutral form explaining our lower DFT and
G2(MP2) PA values for Lys. This finding points to the importance of thoughtful scanning of potential energy surfaces in studies devoted to deriving PAs of multifunctional compounds. It is worth noting here that we have evaluated the energetics of side-chain and backbone amino protonated and salt-bridge (SB) type structures of $[\text { Lys- }+-\mathrm{H}]^{+}$(Figure 1). The SB species features protonated amino and deprotonated carboxylic groups. Protonation at the side-chain amino group is energetically clearly favored, the relative energies of the backbone amino protonated and SB forms are 3.0 and 9.5 $\mathrm{kcal} / \mathrm{mol}$, respectively.

For His, the H\&L and Bouchoux PA values deviate from the other values significantly while our G2(MP2) value $(231.8 \mathrm{kcal} / \mathrm{mol})$ clearly supports Harrison's original value of $231.5 \mathrm{kcal} / \mathrm{mol}$. Bouchoux determined the GB of His applying the thermokinetic method, and the corresponding protonation entropy was approximated by that of 1,3-diaminopentane. In our opinion, this approximation is not fully correct and can lead to the discrepancy between the thermokinetic and G2(MP2) values. It is worth emphasizing here once more that our energetically most favored G2(MP2) structure for protonated His (Figure 2a) is stabilized by a strong H-bond formed by the protonated amino group and the His side-chain. This strong H-bond freezes rotational degrees of freedom that are free for the neutral species leading to a negative $\Delta S_{\text {rot }}$ term that should be taken into account upon deriving the PA of His from its GB. However, Harrison used the $\Delta S_{\text {rot }}=0$ approximation to calculate the PA of His and our G2(MP2) result supports this approach. This apparent contradiction can be resolved by considering that His bears two nearly equally basic protonation sites (amino and side-chain $\mathrm{Ns}$ ) and that the energy difference between the two protonated forms (Figure 2a and $\mathrm{b}$ ) is very small $(-0.8$ and $0.05 \mathrm{kcal} / \mathrm{mol}$ at the DFT and G2(MP2) levels, respectively). In fact, this energy difference is so small that both protonated forms should coexist. This leads to a positive protonation entropy term that can have a similar magnitude to that of $\Delta \mathrm{S}_{\text {rot }}$ arising from freezing rotational degrees of freedom. Therefore, the two entropy terms might actually cancel each other, providing a plausible explanation why the $\Delta \mathrm{S}_{\text {rot }}=0$ approximation works fine for His. In summary, we further support Harrison's values for Ser, Pro, Asp, Phe, Glu, His, Lys, and Trp based on the arguments described above.

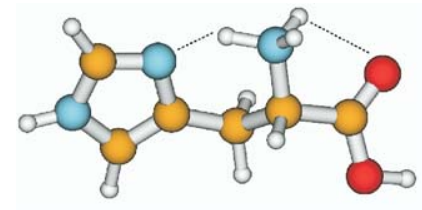

(a)

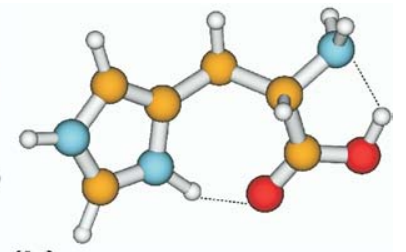

(b)
Figure 2. The energetically most stable protonated His species including backbone (a) and side-chain protonation (b). 


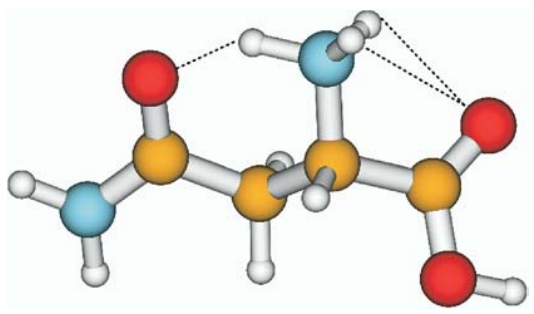

Figure 3. Protonated Asn displaying the strong $-\mathrm{NH} 3+\ldots \mathrm{O}=\mathrm{C}(\mathrm{NH} 2)-\mathrm{H}$-bond.

The third group includes Asn, Gln, Met, and Arg for which some of the recently published PAs, including our computed values, show significant deviation from Harrison's original values. Harrison assigned $220.6 \mathrm{kcal} / \mathrm{mol}$ to the PA of Asn, other values presented in Table 1 are all higher than this including the G2(MP2) value of 222.4 $\mathrm{kcal} / \mathrm{mol}$. According to our calculations, the energetically most favored protonated Asn species (Figure 3) is stabilized by a strong $-\mathrm{NH}_{3}{ }^{+} \ldots \mathrm{O}=\mathrm{C}\left(\mathrm{NH}_{2}\right)$-hydrogen bond accommodated in a 6-membered ring. The structure provides good, albeit not ideal, geometrical arrangement for this hydrogen bond (the $\mathrm{H}_{2} \mathrm{~N}_{\alpha}{ }^{+}-\mathrm{H}$. . O bond angle is $147.8^{\circ}$ ). Because of the formation of this strong H-bond, approximation of $\Delta S$ for Asn with the pure translational entropy term neglecting rotational factors is most probably erroneous. Therefore, we suggest assigning our G2(MP2) value of $222.4 \mathrm{kcal} / \mathrm{mol}$ to the PA of Asn. It is worth noting here that Harrison has already stated the possible short-coming of the $\Delta \mathrm{S}_{\text {rot }}=0$ approximation for Asn. For this reason, he has provided a secondary PA value for Asn by arbitrarily assuming $\Delta \mathrm{S}_{\text {rot }}=-10 \mathrm{cal}$ $\mathrm{mol}^{-1} \mathrm{~K}^{-1}$. This yields a PA of $223.6 \mathrm{kcal} / \mathrm{mol}$ that is in reasonable agreement with our computational data.

Analogously, Harrison has provided secondary PA values for Gln and Glu (Gln: 225.0 and Glu: 226.4 $\mathrm{kcal} / \mathrm{mol}$ ) in addition to the original values (Gln: 220.0 and Glu: $223.4 \mathrm{kcal} / \mathrm{mol}$ ) by arbitrarily assuming $\Delta \mathrm{S}_{\text {rot }}$ $=-10 \mathrm{cal} \mathrm{mol}^{-1} \mathrm{~K}^{-1}$. While for Glu the original PA is in reasonable agreement with the newer data at hand, especially with our G2(MP2) value of $224.7 \mathrm{kcal} / \mathrm{mol}$, this is not the case for Gln. Here, the secondary PA including the $\Delta S_{\text {rot }}$ correction is closer to the newer data (G2(MP2) value of $230.5 \mathrm{kcal} / \mathrm{mol})$, although an agreement is not observed. These observations indicate that rotational entropy contributions may be neglected for Glu, but not for Gln. Moreover, it indicates that rotational entropy contributions should be much larger than the arbitrarily assigned value of $-10 \mathrm{cal} \mathrm{mol}^{-1}$ $\mathrm{K}^{-1}$. For this reason, the neglect of rotational entropy contributions, when transforming the GB of Gln to the corresponding PA, results in severe underestimation of the latter. As a consequence, in the Harrison PA scale Gln is predicted to be less basic than Glu. This clearly contradicts chemical intuition since the $-\mathrm{NH}_{3}{ }^{+} \ldots \mathrm{O}=\mathrm{C}\left(\mathrm{NH}_{2}\right)-$ hydrogen bridge is anticipated to be much stronger than $-\mathrm{NH}_{3}{ }^{+} \ldots \mathrm{O}=\mathrm{C}(\mathrm{OH})-$. This should lead to extra stabilization of the charged amino terminus of Gln in comparison to Glu. This apparent inconsistency of the Harrison's original PA scale can be resolved by assuming the $\Delta \mathrm{S}_{\text {rot }}=0$ approximation valid for Glu, but not for Gln. This is further supported by a comparison of Gln and Asn. Due to the extra methylene group, Gln offers a more ideal arrangement for hydrogen bonding between the protonated N-terminal amine group and the basic side chain (Figure 4, $\mathrm{H}_{2} \mathrm{~N}_{\alpha}{ }^{+}-\mathrm{H}$. . .O bond angle of $168.7^{\circ}$ ) than does Asn $\left(\mathrm{H}_{2} \mathrm{~N}_{\alpha}{ }^{+}-\mathrm{H}\right.$. . . O bond angle of $\left.147.8^{\circ}\right)$ leading to a stronger $\mathrm{H}$-bond for the former. As we have already shown, rotational entropy contributions are important for Asn. This indicates that for Gln rotational entropy contributions cannot be neglected and we suggest assigning the PA of Gln to our G2(MP2) value of 230.5 $\mathrm{kcal} / \mathrm{mol}$.

Arg is protonated on its side chain and the charged guanidine group is stabilized by strong H-bonds involving the terminal amino and carboxyl groups (Figure 1, Supporting Information). Due to the strength of these interactions it is expected that the $\Delta S_{\text {rot }}=0$ approximation for Arg is not satisfactory. This is supported by the PA tabulated by H\&L (251.2 kcal/mol), which exceeds Harrison's value by $6.4 \mathrm{kcal} / \mathrm{mol}$. Considering the robust performance of the G2(MP2) method for the other AAs, we suggest assigning the PA of Arg to our value of $250.2 \mathrm{kcal} / \mathrm{mol}$. Harrison's secondary PA given for Arg assumes $\Delta \mathrm{S}_{\mathrm{rot}}=-10 \mathrm{cal}$ $\mathrm{mol}^{-1} \mathrm{~K}^{-1}$ and gives a PA of $248.7 \mathrm{kcal} / \mathrm{mol}$, which is in reasonable agreement with our G2(MP2) value. It is worth noting here that Rak et al. [32] determined the PA of Arg applying detailed scans of the conformation spaces of the neutral and protonated forms and coupled cluster calculations to derive the final protonation energetics. Their PA of $256.3 \mathrm{kcal} / \mathrm{mol}$ significantly differs from our G2(MP2) value of $250.2 \mathrm{kcal} / \mathrm{mol}$. While it is not clear which reasons are responsible for this deviation, we note that their method predicts an overestimated PA (214.3 kcal/mol) for Gly as well. For Gly the G2(MP2) PA (211.8 kcal/mol) is close to the PA (210.9 $\mathrm{kcal} / \mathrm{mol}$ ) derived from variable temperature equilibrium [9] experiments.

Relatively few independent PA values are available for Met and our DFT and G2(MP2) values are clearly larger (224.0 and $223.7 \mathrm{kcal} / \mathrm{mol}$, respectively) than the original Harrison value of $221.1 \mathrm{kcal} / \mathrm{mol}$. A plausible

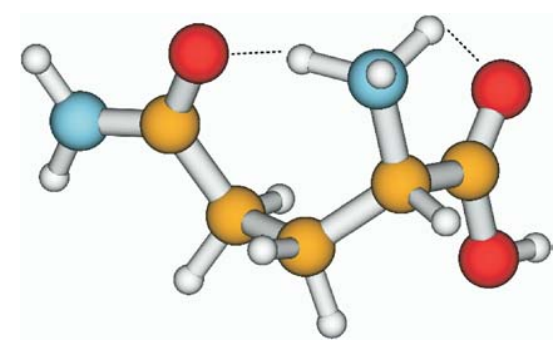

Figure 4. Protonated Gln displaying the strong $-\mathrm{NH} 3+\ldots \mathrm{O}=\mathrm{C}(\mathrm{NH} 2)-\mathrm{H}-$ bond. 


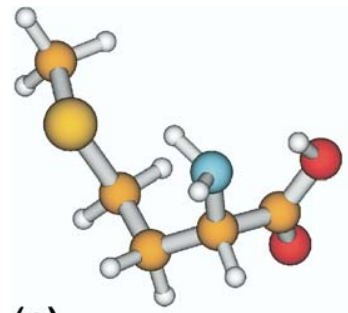

(a)

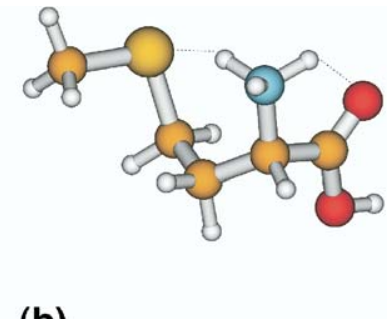

(b)

Figure 5. The energetically most favored (a) neutral and (b) protonated Met structures.

explanation can be obtained by examining the structures of the most stable neutral and protonated forms (Figure $5 \mathrm{a}$ and b). Neutral Met shows a relatively weak $\mathrm{NH}_{2} \ldots$. S hydrogen bond while the $\mathrm{NH}_{3}{ }^{+} \ldots . \mathrm{S}$ interaction in the protonated from is no doubt stronger. The strong $\mathrm{H}$-bond induces a negative $\Delta \mathrm{S}_{\text {rot }}$ upon protonation. Harrison's Met PA was obtained from the corresponding GB assuming $\Delta \mathrm{S}_{\mathrm{rot}}=0$; this approximation is most likely not valid for Met. This possible shortcoming was anticipated by Harrison and he has given a secondary PA assuming $\Delta \mathrm{S}_{\text {rot }}=-10 \mathrm{cal} \mathrm{mol}^{-1} \mathrm{~K}^{-1}$. This yields a PA of $224.1 \mathrm{kcal} / \mathrm{mol}$ which is in excellent agreement with our G2(MP2) value of $223.7 \mathrm{kcal} / \mathrm{mol}$. For this reason, we suggest reassigning the PA of Met to our G2(MP2) value of $223.7 \mathrm{kcal} / \mathrm{mol}$.

Combining the new PA values of Asn, Gln, Arg, and Met with the corresponding GBs of reference [8] tabulated at $298 \mathrm{~K}$, one can easily calculate $\Delta \mathrm{S}_{\text {rot }}$ using eq 1. Such calculations result in $-5.9,-28.6,-18.2$, and -8.8 $\mathrm{cal} \mathrm{K}^{-1} \mathrm{~mol}^{-1}$ rotational entropy for Asn, Gln, Arg, and Met, respectively.

\section{Conclusions}

Harrison's PA scale for AAs and corresponding data from recent literature were reevaluated in the present paper with the help of DFT and G2(MP2) calculations. The available data suggest that neglect of the rotational part of the protonation entropy term can lead to significant errors upon transforming GBs into PAs. Careful investigation of the available PA data and analysis of the strength of $\mathrm{H}$-bonding in protonated AAs indicate that the PAs of Asn, Gln, Met, and Arg need reassignment to $222.4,230.5,223.7$, and $250.2 \mathrm{kcal} / \mathrm{mol}$, respectively. For the other AAs, the original Harrison data are further supported. Most notably, the $\Delta \mathrm{S}_{\text {rot }}=0$ approximation is found to work reasonably for His. This phenomenon is explained by the positive entropy term arising from the nearly equi-energetic backbone and side-chain protonation sites that can cancel the negative $\Delta \mathrm{S}_{\text {rot }}$. The revised PA data suggest new protonation entropies for Arg, Asn, Gln, and Met to be -18.2; -5.9; -28.6 , and $-8.8 \mathrm{cal} \mathrm{K}^{-1} \mathrm{~mol}^{-1}$, respectively.

\section{Acknowledgments}

$\mathrm{BP}$ and SS are indebted to the Deutsche Forschungsgemeinschaft (SU 244/3-1) for financial support. CB was supported by a fellowship of the DKFZ International Ph.D. Program.

\section{References}

1. Creighton, T. E. Proteins: Structures and Molecular Properties; W. H. Freeman and Company: New York 1993, pp 1-473.

2. Paizs, B.; Suhai, S. Fragmentation Pathways of Protonated Peptides. Mass Spectrom. Rev. 2005, 24, 508-548.

3. Harrison, A. G.; Young, A. B. Fragmentation of Protonated Oligoalanines: Amide Bond Cleavage and Beyond. J. Am. Soc. Mass Spectrom. 2004, 15, 1810-1819.

4. Rakov, V. S.; Borisov, O. V.; Whitehouse, C. M. Establishing LowEnergy Sequential Decomposition Pathways of Leucine Enkephalin and Its N- and C-Terminus Fragments Using Multiple-Resonance CID in Quadrupolar Ion Guide. J. Am. Soc. Mass Spectrom. 2004, 15, 1794-1809.

5. Paizs, B.; Suhai, S. Towards Understanding the Tandem Mass Spectra of Protonated Oligopeptides. I: Mechanism of Amide Bond Cleavage. J. Am. Soc. Mass Spectrom. 2004, 15, 103-113.

6. Paizs, B.; Suhai, S. Towards Understanding Some Ion Intensity Relationships for the Tandem Mass Spectra of Protonated Peptides. Rapid Commun. Mass Spectrom. 2002, 16, 1669-1702.

7. Paizs, B.; Suhai, S. Combined Quantum Chemical and RRKM Modeling of the Main Fragmentation Pathways of Protonated GGG. II. Formation of $b(2), y(1)$, and $y(2)$ ions. Rapid Commun. Mass Spectrom.2002, 16, 375-389.

8. Harrison, A. G. The Gas-Phase Basicities and Proton Affinities of Amino Acids and Peptides. Mass Spectrom. Rev. 1997, 16, 201-217and references therein.

9. Moet-Ner, M.; Hunter, E. P.; Field, F. H. Ion Thermochemistry of Low Volatility Compounds in the Gas Phase: I. Intrinsic Basicities of $\alpha$-Amino Acids. J. Am. Chem. Soc. 1979, 101, 686-698.

10. Yamdagni, R.; Kebarle, P. Gas-Phase Basicities of Amines. Hydrogen Bonding in Proton-Bound Amine Dimers and Proton-Induced Cyclization of $\alpha, \omega$-Diamines. J. Am. Chem. Soc. 1973, 95, 3504-3510.

11. Uggerud, E. The Unimolecular Chemistry of Protonated Glycine and the Proton Affinity of Glycine: A Computational Model. Theor. Chem. Acc. 1997, 97, 313-316.

12. Frisch, M. J.; Trucks, G. W.; Schlegel, H. B.; Scuseria, G. E.; Robb, M. A.; Cheeseman, J. R.; Montgomery, J. A., Jr.; Vreven, T.; Kudin, K. N.; Burant, J. C.; Millam, J. M.; Iyengar, S. S.; Tomasi, J.; Barone, V.; Mennucci, B.; Cossi, M.; Scalmani, G.; Rega, N.; Petersson, G. A.; Nakatsuji, H.; Hada, M.; Ehara, M.; Toyota, K.; Fukuda, R.; Hasegawa, J.; Ishida, M.; Nakajima, T.; Honda, Y.; Kitao, O.; Nakai, H.; Klene, M.; Li, X.; Knox, J. E.; Hratchian, H. P.; Cross, J. B.; Bakken, V.; Adamo, C.; Jaramillo, J.; Gomperts, R.; Stratmann, R. E.; Yazyev, O.; Austin, A. J.; Cammi, R.; Pomelli, C.; Ochterski, J. W.; Ayala, P. Y.; Morokuma, K.; Voth, G. A.; Salvador, P.; Dannenberg, J. J.; Zakrzewski, V. G.; Dapprich, S.; Daniels, A. D.; Strain, M. C.; Farkas, O.; Malick, D. K.; Rabuck, A. D.; Raghavachari, K.; Foresman, J. B.; Ortiz, J. V.; Cui, Q.; Baboul, A. G.; Clifford, S.; Cioslowski, J.; Stefanov, B. B.; Liu, G.; Liashenko, A.; Piskorz, P.; Komaromi, I.; Martin, R. L.; Fox, D. J.; Keith, T.; Al-Laham, M. A.; Peng, C. Y.; Nanayakkara, A.; Challacombe, M.; Gill, P. M. W.; Johnson, B.; Chen, W.; Wong, M. W.; Gonzalez, C.; Pople, J. A.; Gaussian 03, Revision C.02; Gaussian, Inc.: Wallingford, CT, 2004.

13. Afonso, C.; Modeste, F.; Breton, P.; Fournier, F.; Tabet, J.-C.Proton affinities of the Commonly Occurring L-Amino Acids by Using Electrospray Ionization-Ion Trap Mass Spectrometry. Eur. J. Mass Spectrom. 2000, 6, 443-449.

14. Bouchoux, G.; Salpin, J, Y.Gas-Phase Basicity of Glycine, Alanine, Proline, Serine, Lysine, Histidine, and Some of Their Peptides by the Thermokinetic Method.Eur. J. Mass Spectrom. 2003, 9, 391-402.

15. Bouchoux, G.; Buisson, D.-A.; Colas, C.; Sablier, M.Protonation Thermochemistry of $\alpha$-amino Acids Bearing a Basic Residue.Eur. J. Mass Spectrom. 2004, 10, 977-992.

16. McLuckey, S. A.; Cameron, D.; Cooks, R. G. Proton Affinities from Dissociation of Proton-Bound Dimers. J. Am. Chem. Soc. 1981, 103, 1313-1317.

17. Cooks, R. G.; Patrick, J. S.; Katiaho, T.; McLuckey, S. A. Thermochemical Determinations by the Kinetic Method. Mass Spectrom. Rev. 1994, 13, 287-339.

18. Maksic, Z. B.; Kovacevic, B. Towards the Absolute Proton Affinities of $20 \alpha$-Amino Acids. Chem. Phys. Lett. 1999, 307, 497-504.

19. Hunter, E. P.; Lias, S. G. Evaluated Gas-Phase Basicities and Proton Affinities of Molecules: An Update. J. Phys. Chem. Ref. Data 1998, 27, $413-656$.

20. Lias, S. G.; Liebman, J. F.; Levin, R. D. Evaluated Gas Phase Basicities and Proton Affinities of Molecules; Heats of Formation of Protonated Molecules. J. Phys. Chem. Ref. Data 1984, 13, 695-808.

21. Curtiss, L. A.; Raghavachari, K; Trucks, G. W.; Pople; J. A. Gaussian-2 Theory for Molecular Energies of First- and Second-Row Compounds. J. Chem. Phys. 1991, 94, 7221-7320. 
22. Curtiss, L. A.; Raghavachari, K.; Pople J. A. Gaussian-2 Theory Using Reduced Møller-Plesset Orders. J. Chem. Phys. 1993, 98, 12931298.

23. Bouchoux, G.; Sablier, M.; Berruyer-Penaud, F. Obtaining Thermochemical Data by the Extended Kinetic Method. J. Mass Spectrom. 2005, $39,986-997$.

24. Wesdemiotis, C. Entropy Considerations in Kinetic Method Experiments. J. Mass Spectrom. 2005, 39, 998-1003.

25. Ervin, K. M.; Armentrout, P. B. Systematic and Random Errors in Ion Affinities and Activation Entropies from the Extended Kinetic Method. J. Mass Spectrom. 2005, 39, 1004-1015.

26. Drahos, L.; Peltz, . C.; Vékey, K. Accuracy of Enthalpy and Entropy Determination Using the Kinetic Method: Are We Approaching a Consensus? J. Mass Spectrom. 2005, 39, 1016-1024.

27. Paizs, B.; Suhai, S. Comparative Study of BSSE Correction Methods at DFT and MP2 Levels of Theory. J. Comput. Chem. 1998, 19, 575-584.
28. Sun, W.; Kinsel, G. R.; Marynick, D. S. Computational Estimates of the Gas-Phase Basicity and Proton Affinity of Glutamic Acid. J. Phys. Chem. A 1999, 103, 4113-4117.

29. Mezzache, S.; Bruneleau, N.; Vékey, K.; Afonso, C.; Karoyan, P.; Fournier, F.; Tabet, J. C. Improved Proton Affinity Measurements for Proline and Modified Proline Using Triple Quadrupole and Ion Trap Mass Spectrometers. J. Mass Spectrom. 2005, 40, 1300-1308.

30. Kuntz, A. F; Boynton, A. W.; David, G. A.; Colyer, K. A.; Poutsma, J. C. The Proton Affinity of Proline Analogs Using the Kinetic Method with Full Entropy Analysis J. Am. Soc. Mass Spectrom. 2002, 13, 72-81.

31. Schroeder, O. E.; Andriole, E. J.; Carver, K. L.; Colyer, K. E.; Poutsma, J. C. Proton Affinity of Lysine Homologues from the Extended Kinetic Method. J. Phys. Chem. A 2004, 108, 326-332.

32. Rak, J.; Skurski, P.; Simons, J.; Gutowski, M. Low-Energy Tautomers and Conformers of Neutral and Protonated Arginine. J. Am. Chem. Soc. 2001, 123, 11695-11707. 